\title{
Taiwanese Filmmakers Wang Shaudi and Huang Liming
}

\author{
By Jan Uhde
}

Fall 2002 Issue of KINEMA

\section{TAIWANESE FILMMAKERS WANG SHAUDI AND HUANG LIMING IN CONVERSA- TION WITH KINEMA}

After studying theatre in the United States, Wang Shaudi returned to Taiwan to a prolific career in television, directing many hours of TV drama and documentaries, and producing plays before making her first feature film Accidental legend (1996) followed by Yours and Mine (1997). Scriptwriter and producer Huang Liming studied journalism in Taiwan and the United States. She started writing for television sixteen years ago, penning stories for Shaudi's TV dramas. They are currently filming a 20-hour drama special for the fifth anniversary of Taiwan's Public Television Service in 2003. KINEMA spoke to the filmmakers about their first animated feature Grandma and her Ghosts (1998) which was screened at the 2002 Far East Film festival in Udine, Italy.

KINEMA: What do you think of the general situation of animation production in Taiwan? Liming: The first university animation department was set up four years ago at the Tainan Institute of Arts. Most of the work done are shorts, but for many years, there hasn't been animation features produced in Taiwan. As far as I know, there are only Lao Fuzi, Chan Shuo Ah Kwan and Grandma and her Ghosts.

Shaudi: Taiwan has been very strong in doing lower-end animation -- almost nine out of ten Hollywood or Disney animated films have parts done in Taiwan. James Wang of Cuckoo's Nest (a Taiwanese company aka Wang Film Production Co., Ltd.) -- from what I hear -- when he goes to Hollywood, they put out the red carpet for him. It's because he gets a lot of work done. It was a very, very big company. When he first started out, it was the biggest in Asia. But then the Koreans became very competitive in this kind of work and the labour cost became higher and higher in Taiwan so most of the animation work moved to Thailand or to mainland China. Even the company, maybe two thirds of it, has gone to work in mainland China now. So it's hard to say how the animation situation is in Taiwan. On one hand, you have very skilled and experienced animators in Taiwan, and we met some of them for our work on Grandma but on the other, we can probably name only three original feature-length animations from the country: Later on we heard from these professional animators that they were watching and waiting for us to go wrong, to lose our way. I mean, it's just not possible for the movie to be finished within a year -- which it had to, not including the first year when we did the script and submitted it.

LM: We received a government grant for the script -- from the moment we received it, we had one year to finish the film in order to claim the award.

SD: Otherwise they fine you. We would have to pay NT 1 million (almost 30,000 USD) if we did not finish it in time. But you know in Hollywood, with all the big budgets, experience and talent, they usually finish feature-length movies in four, five years with millions of US dollars. The total budget for Grandma was very high for us but it amounted to just USD 1.1 million and we had to finish it within a year so it was like mission impossible.

So why did you decide to go into animation? How did you manage to do the film?

LM: It's totally because of ignorance. Because we didn't know how hard it would be. When we make a feature film, it's normal to finish it in one year. But live action is so different from film animation where you start everything from scratch. However we were looking at the brighter side -- we had this romantic idea of animation. We thought, "Oh, this is great, we don't have to go to the locations, we can create the locations, we can create the characters and we can create every prop without actually buying any!" So we thought it would be a lot of fun. But then came the biggest question because we don't draw. I think animated features usually start with a person who can draw. But neither of us can draw. So we had to find a person who could share the story, who could understand what we wanted, and then create the characters we had in mind.

Looking for the right person took six months. We started work with one animator, but after three months, we had to throw away everything because the communication was very hard. To give you an example, we 
found that animators in Taiwan, their work schedule, were pretty much lined up for years. It's not like feature film workers who usually work on a film for a couple of months and then they have to wait for the next project and so you have people you can gather for your project. For animation, if you want to take people out of their daily line of work, you have to pay extra to get them. We talked to this animator for three months and things turned out exactly the way we didn't want. The drawings looked just like the shorts that are usually used for educational purposes and we didn't want that.

We were lucky eventually to find Richard Madson who is a Taiwanese but his father is American. He looks American but he doesn't speak one word of English. He's an independent cartoonist so he's used to working in a small group We could talk to him and seek out what we wanted from his various drawing styles, unlike the previous cartoonists who usually only had one style, such as the Disney animation style. From that time, we started to move along, We had the story board, we went into a sound studio and Shaudi directed the actors and actresses. The dialogue was acted out in the exact way it should sound. When we presented this to the other animators, they were pretty stunned, pretty impressed. So they stepped forward and said, "OK, let us take over from here."

SD: A few reasons why we could make this film: one was that we were unaware of how difficult it could be. If we think about how we made the film, there is one lesson we learnt and that is, there is no absolutely right or wrong way for any one thing. The second thing was our age. When we began to realize how difficult this was going to be, we thought, we were over forty; if we want to do this, we want to do it well. Otherwise it's pointless because Taiwan hasn't been doing any good animation. And the third thing was, everybody who was familiar with Asian animation would ask us, "You did not work with the Wangs?" They were always surprised. Mr Wang thought since we were not experienced, he hoped we would just give him the script and just watch over it and let his people do the job but Liming and I would not agree to that. The fourth reason was because we found the right partners. One of them is Richard Madson as Liming mentioned. He's very talented. He won a national award when he was nineteen. He used to work with the Wangs as an art labourer. That's the kind of work the Wangs do -- colouring, frame by frame movement and everything in between. So he knew the process, he knew what should be done.

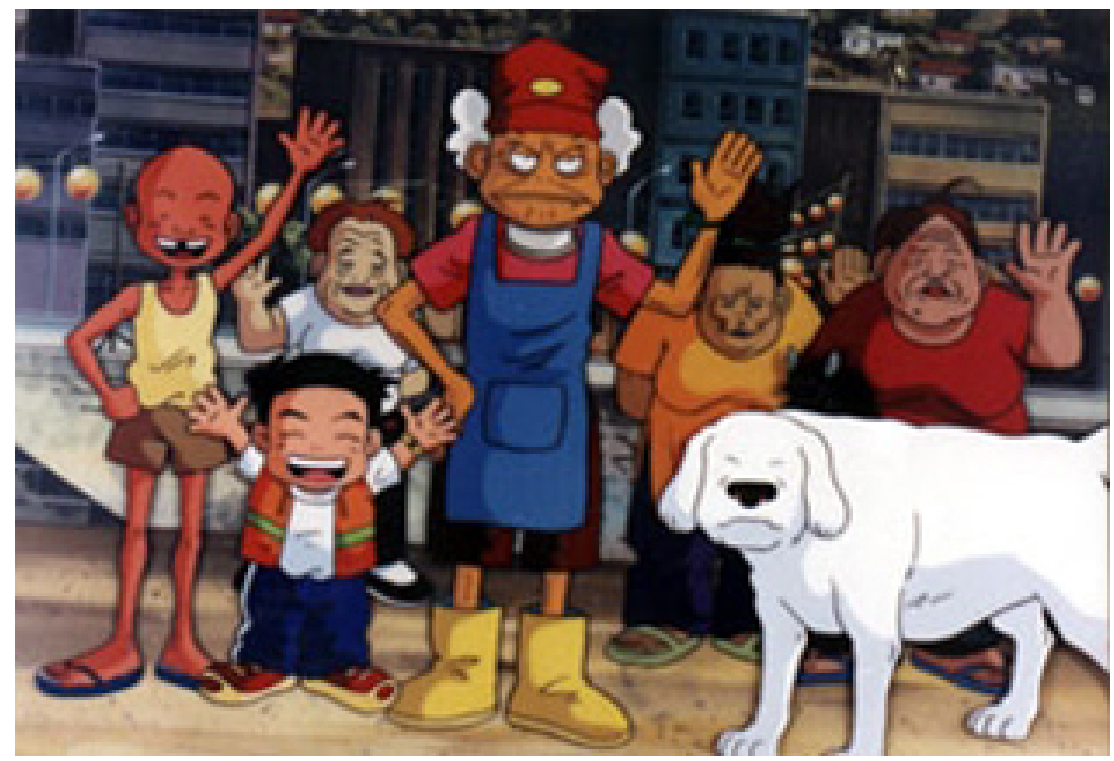

Figure 1: Grandma and her Ghosts

The other person is our Korean partner, Mr Lee Choon-Man of Plus One Animation Ltd. Plus One is a very experienced company, like the Wangs. As I mentioned before, the Koreans became very competitive. When we first met Mr Lee, he asked for a price we could not afford. So Liming, Richard and I went to mainland China to Suzhou to look for a good partner but we could not find one. Finally we turned back to Mr Lee. This time it was very quick because Mr Lee, being a very skilful animator himself, wanted an original feature 
film too, so he asked for the Korean rights and we shared all the expenses and profits. So that way we worked with Plus One. I think they were the key reason why we finished this project within this kind of budget and time limit, plus the fact that Plus One has a different working season. DreamWorks projects and all the Hollywood work comes at a certain time of the year. It was low season then so the whole company was on this job. There were three hundred people on this job, so that's how we got it done. But Liming and I and the production house had almost no income for two years, other than money we borrowed -- we put our house on mortgage. It was a painful period -- I mean it was unthinkable. But anyway, to answer you, those were the reasons.

The other reason, like Liming said, were the other animators who were watching. One of them called up and said, "We know you are in trouble. We want to help." I still remember the night they came, these three big, tall boys. The were like Richard, they'd worked for the Wangs before. They were very, very good. Richard was very ambitious. He wanted to do a lot of things. But we knew little about this line of work. It's group work, it could not be done the way Richard said. But these three guys, they stepped in and called a group of other friends. Another person came in and helped us check everything. It was very, very difficult but that's how we got it done.

\section{Liming, how did the idea and story of Grandma come about?}

LM: It was quite by accident. Actually I was writing another script but in the course of writing, my mother called me and told me all the troubles she was having because she was taking care of my brother's son. He was then five years old. She was complaining because she didn't want the responsibility of taking care of a little boy but she didn't want her grandson to be in the trust of other people, for instance, a maid. My brother had just divorced his wife, both of them had to work and could not take care of the kid. When my mother complained to me and I paid a visit to them, I found that there was a kind of love-hate relationship between them. They relied upon each other. It was not just the boy who was relying on his grandmother. Their lives were bound together. We were all grown up and my mother really had nothing to do in the house -- she was still having a sense of loss when this responsibility was laid upon her. I watched this relationship and I thought, if my five-year-old nephew could sell his grandmother, he'd probably do it! He was eager to get rid of his grandma even though he was so dependent on her but I feel he wouldn't actually do it and so this story emerged.

\section{The blending of superstition and modern life in the film is particularly interesting. What were your thoughts in doing this?}

SD: Well, we sat down and talked about all the funny grandmas we knew. In Asia, a lot of older women have been through a hard life. They are strong but one thing about them is that they are kind of superstitious. They have all kinds of traditional beliefs. They tell you weird things -- you know, strange ways of curing illnesses. They'll say, "Drink this, you'll feel better," or "do that and eat this." For example, we used to work with this very famous actress in Taiwan. She did the sound for grandma in the film. When somebody had the hiccups, she would say, "Sit here and close your eyes." Then she would spit water on you. It's very gross but then -- your hiccups stop! They can be very rude and crude sometimes but really a lot of fun.

We thought the one most important thing was to let the little children get to know grandma's world. We wanted to say grandmas are not so boring. She's not someone you can't understand, someone you can't get close to, and not someone who's just old, ugly and rude! Grandmas have their own world. We thought about how to bring out this world of theirs, so we thought about their beliefs -- the sometimes ridiculous, strong beliefs. We talked about it and we thought that the Pudu feast is one of the most humane acts in Chinese behaviour. Usually the Chinese stick to their families; you know, the Wangs help the Wangs, the Lees help the Lees.

LM: You take care of your own. But the Pudu festival takes care of all wandering ghosts. Wandering ghosts are those who don't have descendants to put food out for them. In the lunar calendar, July is the ghost month, the month when ghosts are allowed to roam in this world and to take care of their unfinished business. So in a sense, it's a frightening month because all the wild ghosts are out, but in another sense, it gives you a chance to be kind to others, even if they are ghosts.

SD: It's funny if you could see the table that people put out for the ghosts -- sometimes there are even sunglasses and toothpaste and wash basins. It's very considerate, as if all these ghosts are really tired 
wanderers or travellers! From the tables you see the relationships between the living and the dead in the traditional way of thinking.

What about the Japanese animator Hayao Miyazaki? Were you influenced by his style and imagery in the making of Grandma?

LM: Miyazaki always starts his story with substantial feelings, true feelings, and that is also how our movie began. When I started writing the story, I was intrigued by this relationship between my mother and my nephew. At the time I was not thinking of Miyazaki at all. But come to think of it now, the way the story starts is perhaps similar to Miyazaki's although we did not know it then. Image-wise, I think that our lack of resources sometimes made us think harder. If we had a lot of alternatives, then maybe we would have added UFOs and this and that, but because we were limited, we could not make too many movements in the animation, and we had to rather make use of moods in the film. In that respect, Shaudi had more input because of the way she set the tone in the story-telling and whenever she had the chance, she extended the use of mood.

SD: Miyazaki was the first person to make us sit down and watch cartoon animation and really feel for it. Before, we didn't even think about doing animation because it was not interesting, because it was always a legend or fairy tale or Hollywood animation. After Liming's mother called her, she was upset, trying to resolve her mother's problems with her nephew but she could not help much. But when that kind of emotion started the urge to create, it would not have been in the form of animation if not for Miyazaki. His films made her realize that she could write it as a story for animation too. The heart of animation is more about feeling, it's not about action or what kind of fantastic animation we can come up with. So maybe Grandma is in the spirit of Miyazaki because his movies are always about some kind of true feeling.

In the festival catalogue, there's a comment that our animation is made in the style of Miyazaki's films, even the cat is called Kulo and the dog Shilo, Japanese names meaning black and white respectively but actually that's taken from real life.

LM: My dog's name was Shilo because he was white although I didn't know what it meant then. It was actually my uncle's dog. I just remembered I had a dog called Shilo when I was young.

SD: The real life grandmother, Liming's mother, was born during the Japanese occupation and she spoke Japanese. When we were doing the first scene at the start of the movie showing all the grandmas waiting for the light to come in through the skylight, Liming wanted them to speak in Japanese because that's her mother. When she gets together with her close friends, they speak Japanese. People might mistake that to be Japanese but it's an authentic Taiwanese experience. There's also this beautiful harbour town in the film where the grandma lives. We actually went out to this kind of little town to take pictures for the drawings. It's a typical harbour town in Taiwan with fishing families and a mixture of languages -- Mandarin and Taiwanese. If you noticed, grandma speaks Taiwanese to her friends and daughter, but she is forced to speak Mandarin to the little boy because he cannot speak Taiwanese. That's also a very typical experience in Taiwan.

\section{Speaking of Taiwan, how was the film received there?}

SD: For one thing, we won the Best Taiwanese Feature Prize at the Taipei Film Festival in1999. We were in the same competition with Hou Hsiao-hsien's Shanghai Flowers and Tsai Ming-liang's The Hole. The reason why we got the award was because the jury felt these more internationally known films were drifting away from the audience at home and they felt that Grandma and her Ghosts was closer to the audience. So we are not saying we are better, but there's recognition of this point.

Secondly, when Grandma was screened at the festival for the first time, there were thousands of people laughing together -- it was a rare experience for any Taiwanese feature film. People were just crazy afterwards. I still remember this elementary school teacher who came up and said, why don't we clap our hands for these people! So you know, people are really touched by good animation easily, more easily than by live action I think!

The third thing is that we released Grandma and her Ghosts on our own. We did not do it the traditional way. Instead we made more money than we would have in the traditional way. I would suggest every film find its own way of distribution. We had help from a theatre group that was doing children's theatre. They 


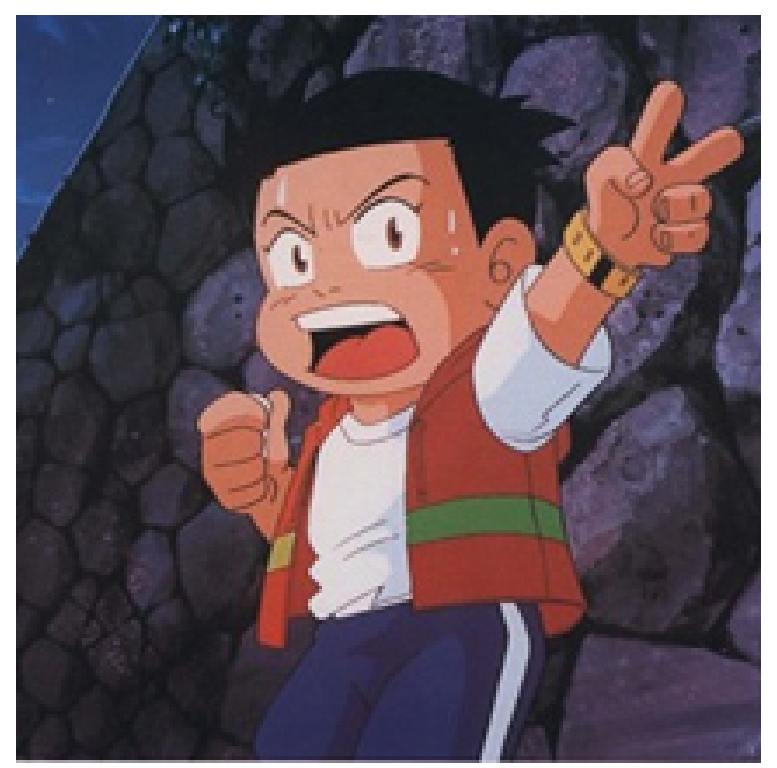

Figure 2: Grandma and her Ghosts

have subscription members and we gave out the right information in the right way. Another thing is that Liming did a lot of merchandising before and during the film's release. For our previous live action films which were advertised the traditional way, I used to run to five radio stations in one day, rushing here and there to tell people to come -- that did not work. But when we put out the merchandise it worked better

LM: The theatrical release took in about NT 5 million. From the VCD rentals alone, the film made about NT 5 million but our share is 50 percent of that. Actually, I'm very happy because the people we worked with all made money.

Shaudi, you mentioned the other day that it's difficult to be a director in Taiwan. Could you comment more on that?

SD: Well, for one thing, because the home market is very small, there's never enough money. You have to work very hard. Because of the lack of money, you don't have enough talent from many fields in film. When John Woo came to Taipei, one of my friends was about to interview him. She asked if there was something I wanted to ask him. I said to ask if it's really great to work in Hollywood. She came back and said, "John Woo said yes! It's so different from working in Hong Kong. I just drop an idea and the computer graphics people and the special effects people come up with the result better than I could ever imagine." And in Taiwan -- I always tell this joke -- in Taiwan, everybody says, so how do we do it, director? Show us! The director has to think down to the last detail how everything should be done. People cannot support their families doing this line of work. It's very precious to have your crew or friends doing the lighting, the camera and all the young people who put in a lot to work long hours for very little money. On the other hand, it's very hard because you never have enough time and money.

Another thing is that the people and the government always emphasize too much on politics and the economy and they seldom put their money, hearts or minds into culture, especially for the movies. There's a lot of ignorance, wrong decisions, wrong policies made in this area. Within this small island of Taiwan, we have more than ninety channels, including cable. There's not enough money and money from advertisements is divided. And so with very small budgets, TV stations start to buy Japanese and Korean series because it's cheaper that way. Movies made in Taiwan are getting smaller budgets and when you do something within a small budget nowadays, with the existence of the satellite, you cannot compete. People don't spend time on low quality programmes anymore. So it's a bad circle.

Having worked in theatre and television, film and now animation, do you have a favourite medium? 
SD: That really hurts to answer. When I was young, I thought I could do everything. And still, a lot of times, if I answer from my heart, I think I can do each of these well. But then again, maybe that's why I still have not come up with a masterpiece in any of these areas! If you ask me, I love to do theatre, I love to do film, I love to do animation and I think it's important to do good TV. So I really don't have an answer yet.

\section{Is there a Taiwanese film director you value in particular?}

LM: Recently, I've been touched by a young man's work. He's doing a trilogy concerning the aborigines in Taiwan. He's been using digital video combined with film camera, giving him more freedom and he's experimenting with a crew of music composers who are aborigines themselves. Together it gives a new feeling to the work. His name is Cheng Wen-tang. (Cheng's first 35mm feature, Somewhere Over the Dreamland, was invited to the $59^{\text {th }}$ Venice IFF.)

SD: We have so many good directors and I really treasure them, for example, Hou Hsiao-hsien. He's important because before, Taiwan was a main source of movie-making in Asia. We put out hundreds of movies, all kinds of movies, especially romantic ones. But when we were growing up, a lot of them were just really rotten, copying one another. Hou Hsiao-hsien was the one who showed us that's not the only way to make movies. Movies are about something else. And Edward Yang, he's shown a different kind of aesthetic: more western but more subtle.

For me, being different is a good thing when you talk about movie-making. Nowadays, we have a lot of documentaries. Taiwan has been quite strong in documentaries. A lot of aboriginal young people are doing documentaries themselves. So you see all these young directors coming from different backgrounds -documentaries, MTV, commercials. It's been quite good for TV movies because feature filmmaking is so slow in Taiwan and so a lot of directors turn to TV movies. Because of public television in the last few years, we've been getting very good works from young directors in TV movies and documentaries. I'm an easily touched person, and many films really move me and teach me because I know how hard it is to work there. There are a lot of them in the boiling water with me!

The respected Taiwanese film critic Peggy Chiao once wrote that you are an inspiration to many young filmmakers in Taiwan.

LM: Tsai Ming-liang was a student of Shaudi's when she was teaching drama at the Chinese Cultural University. I think that's why Peggy said that. The director I just mentioned, Cheng Wen-tang, was also a student of Shaudi's.

SD: I realized very early that movie-making is teamwork. It's work I like but it's not personal work There are a lot of young directors coming out from our studio -- our production house (Rice Film International). Many Taiwanese directors who emerged either worked with us for a period of time, or was my student. But that's not the most important thing. Anybody could do that. If you really value creative talent, creative passion, within another person, if you really care about that, then it's like nature -- the young ones will grow and they turn out fantastic, brilliant work. When they do something really good, you can share it with them. When they do something bad -- when I do something bad -- they'd say , "Oh god, it's awful!" behind my back. It's fun that way.

(Interviewed for KINEMA by Jan Uhde and Yvonne Ng in Udine, Italy, April 2002.)

\section{Author Information}

Jan UHDE is Professor Emer. (Film Studies) at the University of Waterloo, Ontario, Canada. Born in Brno, Czech Republic. Graduated (MA) from the Faculty of Arts, Masaryk University, Brno; PhD received at the University of Waterloo, Ontario, Canada. He taught at the University of Waterloo (1970-2012) where he founded a General and Honours BA program in Film Studies at the Department of Fine Arts.

Publications: Latent Images: Film in Singapore Second edition, with Yvonne Ng Uhde (Ridge Books, National University Press of Singapore, 2010); Latent Images: Film in Singapore, with Yvonne Ng Uhde (Oxford University Press, 2000); Latent Images: Film in Singapore CD-ROM (2003, co-author); Vision and Persistence: Twenty Years of the Ontario Film Institute (University of Waterloo Press, 1990) and Ontario Film 


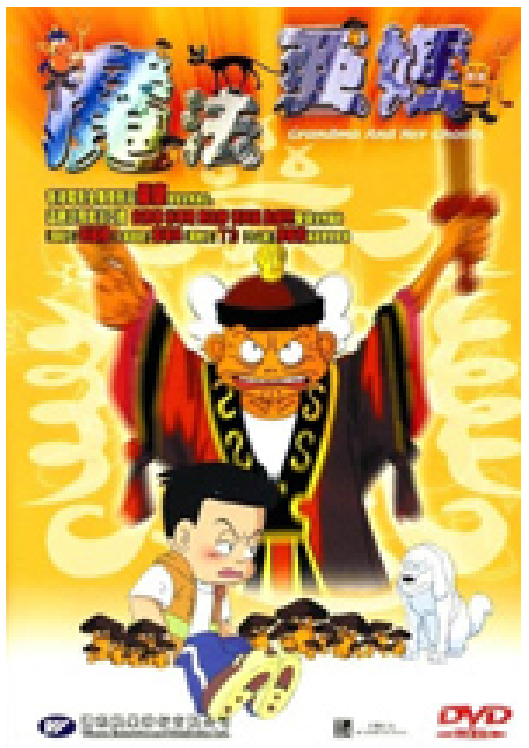

Figure 3: Grandma and her Ghosts DVD

Institute Programming Activities Index 1969-1989 (Toronto: Ontario Science Centre, 1990). He co-edited the Place in Space: Human Culture in Landscape (Proceedings from the Second International Conference of the Working Group "Culture and Landscape" of the International Association of Landscape Ecology, Pudoc Scientific Publishers, Wageningen, Holland, 1993). Jan Uhde has published articles and reviews in several countries (including Canada, USA, Germany, Italy), participated in international juries at film festivals and presented papers at international conferences in North America and Europe. In 1998/99, he was a visiting researcher at the School for Film and Media Studies, Ngee Ann Polytechnic, Singapore.

His professional and research interests focus on Singapore cinema; the identification and distancing mechanisms of the film viewer; the non-authored modifications and manipulation of films; and specific aspects of film history, including the Central European cinema.

He founded KINEMA in 1993. 